\title{
PREFACE: 10TH INTERNATIONAL CONFERENCE ON MULTIPHASE FLOW 2019
}

We are very pleased to present this Special Issue of Multiphase Science and Technology containing selected articles presented at the 10th International Conference on Multiphase Flow (ICMF 2019).

ICMF is recognized as the largest and most important international scientific forum to discuss research, development, and applications of multiphase flow. ICMF 2019 was held in Rio de Janeiro, Brazil, from May 19 to May 24, 2019, and was hosted by three major Brazilian Universities: the University of São Paulo (USP) at São Carlos School of Engineering, University of Campinas (UNICAMP), and Rio de Janeiro State University (UERJ). The conference was promoted by the Brazilian Society of Mechanical Sciences and Engineering (ABCM) and the European Research Community on Flow, Turbulence and Combustion (ERCOFTAC).

Delegates from 31 countries (a remarkable figure!) were present at the event in Rio, and a total of 683 people attended the ICMF2019. After a careful selection of papers, 554 oral and 35 poster presentations were delivered at the conference, including 5 plenary and 7 keynote lectures. Overall, $25 \%$ of the attendees came from Asia, $27 \%$ from the Americas, $44 \%$ from Europe, and $4 \%$ from other regions all around the world.

The technical program, which featured 589 papers distributed in 25 technical sections, attested how diverse and multi-disciplinary ICMF 2019 has been. The topics computational and experimental methods for multiphase flows, bubbly and droplet flows, particle-laden flows, modeling of multiphase flows, and turbulence in multiphase flow were very well represented once again. It is worth noticing the importance that the topics boiling, condensation, evaporation, micro- and nano-scale multiphase flows, and multiphase flow in heat and mass transfer have gained in this edition. Not to mention topics such as bio-fluids, environmental and geophysical flows, fluid-structure interactions, colloidal and suspension dynamics, interfacial and reactive multiphase flows, granular media, fluidization, cavitation, nucleation, mixing, collision, agglomeration and breakup and instabilities, all of them contributing with a significant number of papers. For this special issue, state-of-the-art works on multiphase flow that include CFD applications, experimental techniques and processes, and industrial applications were selected.

We would like to thank the ICMF-2019 scientific committee and scientific editors for the careful selection of papers. The papers selected for this special issue are the results of a process that involved many people and we would like to dedicate it to all those who have made their best efforts to contribute to this publication.

\section{Guest Editors:}

Oscar M.H. Rodriguez

Industrial Multiphase Flow Laboratory (LEMI)

Department of Mechanical Engineering

São Carlos School of Engineering

University of São Paulo (USP)

São Carlos, SP, Brazil 
Jader R. Barbosa Jr.

POLO Research Labs for Emerging Technologies in Cooling and Thermophysics

Federal University of Santa Catarina

88040-900, Florianopolis, SC, Brazil 